\title{
Energy expenditure of Gambian women during peak agricultural activity measured by the doubly-labelled water method
}

\author{
BY J.SINGH, A. M. PRENTICE*, E. DIAZ, W. A. COWARD, J. ASHFORD, \\ M. SAWYER AND R. G. WHITEHEAD \\ MRC Dunn Nutrition Unit, Milton Road, Cambridge CB4 IXJ, and Keneba, The Gambia
}

(Received 23 February 1989 - Accepted 29 March 1989)

The doubly-labelled water $\left({ }^{2} \mathrm{H}_{2}{ }^{18} \mathrm{O}\right)$ method was used to measure total energy expenditure (TEE) in ten non-pregnant, non-lactating (NPNL), six pregnant (P) and fourteen lactating (L) women in a rural Gambian community. Measurements were made on free-living subjects at a period of peak energetic stress when high agricultural work loads coincided with a hungry season to induce moderately severe negative energy balance. TEE averaged 10.42 (SD 2.08) MJ/d, equivalent to 1.95 (SD 0.38) times resting metabolic rate (RMR). The energy cost of physical activity plus thermogenesis, derived as TEE - RMR, averaged 4.94 (SD 1.96) $\mathrm{MJ} / \mathrm{d}$. Expressed per $\mathrm{kg}$ body-weight $(103 \mathrm{~kJ} / \mathrm{kg}$ per d) this component of expenditure was 2.5 times greater than comparative values from inactive, affluent women studied previously ( $39 \mathrm{~kJ} / \mathrm{kg}$ per d). Estimated energy intake (EI) in a subset of the women ( $n$ 13) was only 4.80 (SD 1.58) $\mathrm{MJ} / \mathrm{d}$, yielding an apparent deficit of $6.08 \mathrm{MJ} / \mathrm{d}$ between EI and TEE. Weight changes suggested that endogenous fat oxidation accounted for only about $0.85 \mathrm{MJ} / \mathrm{d}$, leaving an unexplained difference of over $5 \mathrm{MJ} / \mathrm{d}$. Critical analysis of possible errors suggests that the new doubly-labelled water method has provided the most reliable estimates and that the estimates of EI were substantially in error. This finding has important consequences for other food intake studies.

Doubly-labelled water technique: Energy expenditure: Gambian women

Studies of energy balance in marginally nourished populations in the developing world frequently report very low levels of energy intake which appear to be incompatible with the high levels of obligatory physical activity associated with a rural farming life. These discrepancies are not only apparent when reviewing intake and expenditure values from different studies (James \& Shetty, 1982; Prentice, 1984), but also arise within individual studies (Norgan et al. 1974; Bleiberg et al. 1981 ; Lawrence et al. 1987 b; Lawrence, 1988). Such results have contributed to the current interest in mechanisms of adaptation to longterm low energy intakes.

The interpretation of energy balance values becomes even more difficult when seasonal changes have to be considered. In many rural communities working adults use their fat stores to buffer the effects of seasonal food shortages or increases in agricultural work load (Prentice et al. 1981; Prentice, 1984; Dugdale \& Payne, 1987). These changes in bodyweight are often no more than $2-3 \mathrm{~kg}$ over a 4-6-month period, which would contribute only about $0.5 \mathrm{MJ} / \mathrm{d}$ to the overall energy budget (A. Ferro-Luzzi, personal communication). In three rural villages in The Gambia we have previously demonstrated somewhat larger seasonal fat losses of up to $4-5 \mathrm{~kg}$, with an estimated energy equivalence of up to $1.4 \mathrm{MJ} / \mathrm{d}$ (Prentice et al. 1981). However, at the worst time of year even this amount falls considerably short of the apparent deficit between food intake estimated at about $5 \mathrm{MJ} / \mathrm{d}$ and energy expenditure estimated by the factorial method to be about $10 \mathrm{MJ} / \mathrm{d}$ (Lawrence et al. $1987 a, b$; Lawrence \& Whitehead, 1988). Such a large discrepancy

* For reprints. 


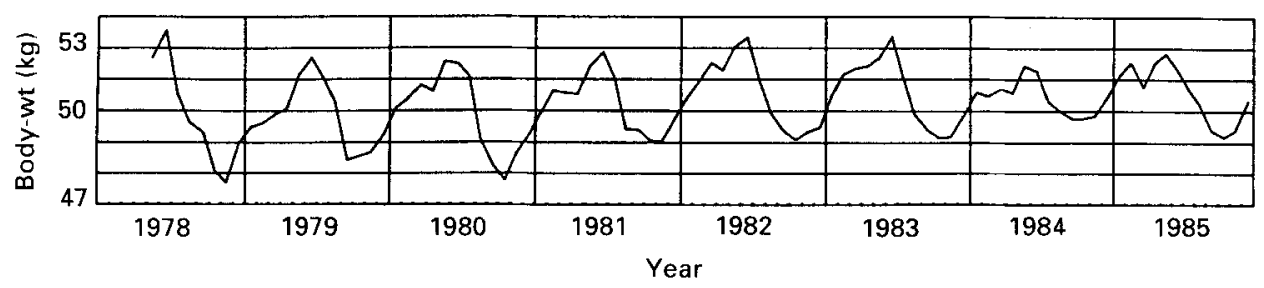

Fig. 1. Seasonal weight changes in rural Gambian women. Derived by analysis of over 11000 data-points after statistical correction for the influence of pregnancy and lactation (Cole, 1989).

must be the result of a serious error in one or more of the techniques used to assess food intake, energy expenditure or the energy derived from the oxidation of body fat.

The present study used the recently developed doubly-labelled water method (DLW) to provide an independent estimate of energy expenditure in an attempt to resolve these discrepancies.

\section{METHODS}

The rural, subsistence-farming villages of Keneba, Kantong-Kunda and Manduar in The Gambia have been extensively described elsewhere (Prentice, 1984). Annual patterns of food intake and energy expenditure are dominated by sharply-defined wet and dry seasons. During the wet season (July-October) food shortages occur when the previous year's crops begin to run out before the current year's crops have been harvested. The effects of the food shortages are compounded by a heavy agricultural workload at this time of year, and the combined stresses force all working adults into moderately severe negative energy balance (Fig. 1). The present study was performed at the time of maximum agricultural work identified on the basis of activity diary studies over a number of previous years (Lawrence et al. 1987b; Lawrence \& Whitehead, 1988). The energetic stress of reproduction was investigated as an additional variable by studying non-pregnant, non-lactating (NPNL), pregnant (P) and lactating (L) women.

\section{Subjects}

Measurements were made in two phases during consecutive years. Phase 1 measurements were made in late August and early September. Phase 2 measurements were made 2-3 weeks later in September alone. However, the women were engaged in the same activity (weeding rice fields) in both phases, as the rains also started later in the second year.

All women walked distances of $2-7 \mathrm{~km}$ to their rice fields each day, often carrying an infant, water and food. They spent an average of $8 \mathrm{~h}$ at the fields working for $70-80 \%$ of the time. Before leaving for the fields and after returning home the women had to do many other moderately active tasks, including sweeping their compound, drawing water by hand, carrying water, washing clothes, fetching and chopping wood, pounding and winnowing grain, cooking and childcare.

Subject details are given in Table 1. The differences in age and parity between the groups are unlikely to have any significant influence on work patterns and energy expenditure. The low parity in the NPNL groups arises from the inclusion of a number of subfertile women in phase 1. These subjects had a significantly higher body fat content than those in phase $2(P<0.005)$ and must be considered to be atypically well-nourished for this community. Average fatness assessed from total body water in other groups ranged from $15 \cdot 4$ to $22 \cdot 1 \%$. Mean values from affluent women in Cambridge, UK, fall in the range $28-30 \%$ when measured using the same technique. The $\mathrm{P}$ women were studied in the second and 
Table 1. Characteristics of rural Gambian women participating in the study (Mean values and standard deviations)

\begin{tabular}{|c|c|c|c|c|c|c|c|c|c|c|c|c|c|c|c|c|c|}
\hline \multirow{3}{*}{$n \ldots$} & \multicolumn{6}{|c|}{ Phase 1} & \multicolumn{5}{|c|}{ Phase 2} & \multicolumn{6}{|c|}{ Combined } \\
\hline & \multicolumn{2}{|c|}{$\begin{array}{c}\text { NPNL } \\
6\end{array}$} & \multicolumn{2}{|c|}{$\begin{array}{l}P \\
6\end{array}$} & \multicolumn{2}{|l|}{$\begin{array}{l}\mathrm{L} \\
5\end{array}$} & \multicolumn{2}{|c|}{$\begin{array}{c}\text { NPNL } \\
4\end{array}$} & \multirow[t]{2}{*}{$\begin{array}{l}\mathrm{P} \\
0\end{array}$} & \multicolumn{2}{|c|}{$\begin{array}{l}\mathrm{L} \\
9\end{array}$} & \multicolumn{2}{|c|}{$\begin{array}{c}\text { NPNL } \\
10\end{array}$} & \multicolumn{2}{|c|}{$\begin{array}{l}P \\
6\end{array}$} & \multicolumn{2}{|c|}{$\begin{array}{c}\mathrm{L} \\
14\end{array}$} \\
\hline & Mean & $\mathrm{SD}$ & Mean & SD & Mean & SD & Mean & SD & & Mean & SD & Mean & SD & Mean & SD 1 & Mean & SD \\
\hline Age (years) & 32 & 4 & 24 & 7 & 29 & 10 & 27 & 11 & - & 23 & 7 & 30 & 7 & 24 & 7 & 25 & 9 \\
\hline Parity & 1 & 1 & 3 & 3 & 6 & 3 & 1 & 3 & - & 3 & 3 & 1 & 2 & 3 & 3 & 4 & 3 \\
\hline $\begin{array}{l}\text { Stage of } \\
\text { pregnancy } \\
\text { (weeks) }\end{array}$ & - & - & 20 & 5 & - & & - & & - & - & - & - & - & 20 & 5 & & - \\
\hline $\begin{array}{l}\text { Stage of } \\
\text { lactation } \\
\text { (weeks) }\end{array}$ & - & - & & - & 24 & 4 & - & & - & 20 & 8 & - & & - & - & 20 & 8 \\
\hline Height (m) & $1 \cdot 58$ & 0.04 & 1.66 & $5 \quad 0 \cdot 10$ & $\begin{array}{ll}0 & 1.61\end{array}$ & $0 \cdot 05$ & $1 \cdot 58$ & 0.08 & $8-$ & -1.56 & 0.02 & 1.58 & 0.06 & 1.66 & $60 \cdot 10$ & 1.58 & $8 \quad 0.05$ \\
\hline Initial wt $(\mathrm{kg})$ & $50 \cdot 0$ & $4 \cdot 1$ & $59 \cdot 5$ & $14 \cdot 9$ & $54 \cdot 7$ & $8 \cdot 9$ & $48 \cdot 6$ & $7 \cdot 0$ & - & $-46 \cdot 6$ & $4 \cdot 2$ & $49 \cdot 3$ & $5 \cdot 3$ & $59 \cdot 5$ & 14.9 & $49 \cdot 6$ & $7 \cdot 4$ \\
\hline $\begin{array}{l}\text { Sum of four } \\
\text { skinfolds } \\
(\mathrm{mm})\end{array}$ & 43.4 & $5 \cdot 1$ & $30 \cdot 5$ & $8 \cdot 3$ & $31 \cdot 8$ & $13 \cdot 6$ & $32 \cdot 8$ & $9 \cdot 2$ & - & -25.8 & 4.0 & $39 \cdot 2$ & 8.9 & $30 \cdot 5$ & $8 \cdot 3$ & $27 \cdot 9$ & $12 \cdot 9$ \\
\hline $\begin{array}{l}\text { Body fat } \\
(\%)^{*}\end{array}$ & $28 \cdot 1$ & 4.9 & $22 \cdot 1$ & $4 \cdot 2$ & 20.7 & $7 \cdot 8$ & $16 \cdot 3$ & $4 \cdot 1$ & - & -15.4 & $3 \cdot 2$ & $23 \cdot 4$ & $7 \cdot 4$ & $22 \cdot 1$ & $4 \cdot 2$ & $17 \cdot 3$ & $5 \cdot 7$ \\
\hline
\end{tabular}

NPNL, non-pregnant, non-lactating; $P$, pregnant; L, lactating.

* Calculated from deuterium dilution spaces.

third trimesters, and the $\mathrm{L}$ women at about 56 months post-partum, when milk production was still close to maximal.

The study was approved by the joint MRC/Gambian Government Ethical Committee.

\section{Resting metabolic rate ( $R M R$ )}

RMR was measured on three separate occasions during the isotope measurements (see below) in phase 1 and on a single occasion in phase 2 . After an overnight fast subjects were transported to a quiet air-conditioned room and rested for approximately $30 \mathrm{~min}$ before the measurements were made for a further $30 \mathrm{~min}$ using an open-circuit ventilated hood system in phase 1 and Douglas bags in phase 2. Gas concentrations were measured using a Servomex OA 580 paramagnetic oxygen analyser (Taylor Instrument Analytics Ltd, Crowborough, Sussex, UK) and a Model SSI infra-red carbon dioxide analyser (Analytical Development Company Ltd, Herts, UK). Air flow was controlled at a nominal rate of 30 1/min, measured using a Rotameter flow-meter (KDG Flowmeters Ltd, Burgess Hill, Sussex, UK) and corrected to STPD for calculation of metabolic rate using the Weir formula (Weir, 1949).

$$
\text { DLW }\left({ }^{2} \mathrm{H}_{2}{ }^{18} \mathrm{O}\right) \text { method }
$$

Total free-living energy expenditure (TEE) was measured using the DLW method (Lifson et al. 1955). The principle of the technique together with full details of experimental method, calculation of results, validation and likely limits of error are published elsewhere (Lifson \& McClintock, 1966; Schoeller \& van Santen, 1982; Schoeller, 1983; Coward \& Prentice, 1985; Prentice et al. 1985; Coward et al. 1986; Coward, 1988; Prentice, 1988). In the present study subjects received an oral dose of $0.05 \mathrm{~g}^{2} \mathrm{H}_{2} \mathrm{O} / \mathrm{kg}$ and $0.15 \mathrm{~g} \mathrm{H}_{2}{ }^{18} \mathrm{O} / \mathrm{kg}$ after an overnight fast and collection of a pre-dose, baseline urine sample. Post-dose urine samples were collected after a further $4 \mathrm{~h}$ fasted equilibration period, during which all voluntary urine produced was measured and sampled to allow for correction of unabsorbed 
dose. In practice this correction is usually trivial and could be ignored. Serial mid-morning urine samples were collected for the next $14 \mathrm{~d}$. Isotope enrichment levels were measured using a VG Isogas Aquasira dual isotope-ratio mass-spectrometer (VG Isogas Ltd, Middlewich, Cheshire, UK).

$\mathrm{CO}_{2}$ production rates $\left(F_{\mathrm{CO}_{2}}\right)$ were calculated using Coward's modification of the original Lifson (Lifson \& McClintock, 1966) formula (Coward \& Prentice, 1985; Coward et al. 1986)

$$
F_{\mathrm{CO}_{2}}=\frac{1}{2}\left(K_{\mathrm{O}} D_{\mathrm{O}} / I_{\mathrm{O}}-K_{\mathrm{D}} D_{\mathrm{D}} / I_{\mathrm{D}}\right)
$$

where $K_{0}$ and $K_{\mathrm{D}}$ are rate-constants for ${ }^{18} \mathrm{O}$ and ${ }^{2} \mathrm{H}$ (deuterium) disappearance, $D_{\mathrm{O}}$ and $D_{\mathrm{D}}$ are doses of ${ }^{18} \mathrm{O}$ and ${ }^{2} \mathrm{H}$, and $I_{\mathrm{O}}$ and $I_{\mathrm{I}}$, are zero-time intercepts of the ${ }^{18} \mathrm{O}$ and ${ }^{2} \mathrm{H}$ disappearance curves.

Fractionation corrections were incorporated into eqn (1) using values of 0.99 for ${ }^{2} \mathrm{H}_{2} \mathrm{O}$, 1.04 for $\mathrm{C}^{18} \mathrm{O}_{2}$ and 0.93 for $\mathrm{H}_{2}{ }^{18} \mathrm{O}$ to give:

$$
\begin{aligned}
& F_{\mathrm{CO}_{2}}=\frac{1}{2}\left[0.99 \times K_{\mathrm{D}} V_{\mathrm{D}} / I_{\mathrm{D}}+(1-x) K_{\mathrm{D}} V_{\mathrm{D}} / I_{\mathrm{D}}+1.04 K_{\mathrm{O}} V_{\mathrm{o}} / I_{\mathrm{O}}\right] \\
& -\frac{1}{2}\left[0.93 \times K_{\mathrm{D}} V_{\mathrm{D}} / I_{\mathrm{D}}+(1-x) K_{\mathrm{D}} V_{\mathrm{D}} / I_{\mathrm{D}}\right]
\end{aligned}
$$

where $x$ represents the fraction of water undergoing isotopic fractionation. Experiments by Schoeller et al. (1986) and in our laboratory (W. A. Coward, P. R. Murgatroyd and A. M. Prentice, unpublished results) have demonstrated that only water lost from the lungs and as non-sweating transcutaneous evaporation is fractionated. The value $x$ is calculated as: (respiratory water losses + non-sweating transcutaneous losses)/total water turnover. It is now agreed that Lifson's (Lifson \& McClintock, 1966) original assumption of $x=0.5$ is far too high for human studies, even in temperate conditions, and values between 0.25 and 0.35 have been found to be more appropriate (Coward et al. 1986; Schoeller et al. 1986; Coward, 1988; Schoeller, 1988). In tropical conditions the denominator is markedly increased (see Results, p. 321), but there is no evidence to suggest that the numerator will be significantly increased. First, respiratory water losses are a function of respiratory volume and the humidity of in-breathed air. The latter was high during the wet season when these measurements were made, thus tending to suppress respiratory fractionation. Nonsweating transcutaneous losses are a function of skin temperature and the humidity of the micro-environment close to the skin surface. Skin temperature is regulated within fairly narrow limits by sweating. Sweating will also tend to increase the humidity of the microenvironment, thus suppressing non-sweating losses. The high ambient humidity will have the same effect. All these factors indicate that a substantially lower fractionation assumption is required under the Gambian conditions. On the basis of the average calculations for individualized values of $x$ (see below) we have chosen to present the values using $x=0 \cdot 15$, and to recalculate the values using two further assumptions, in order to demonstrate the maximum possible errors incurred if this assumption is incorrect. The first uses the unreasonable assumption that non-sweating transcutaneous losses are four times greater than those assumed by Schoeller (1988) or measured by us in temperate conditions (Coward, 1988). This would lead to a value for $x$ of 0.35 . The second assumption uses a method for predicting individual values for $x$ computed as $x=\left[0.5 \times F_{\mathrm{Co}_{2}}+500\right] / F_{\mathrm{H}_{2} \mathrm{O}}$ where: $F_{\mathrm{CO}_{2}}$ is the crude $\mathrm{CO}_{2}$ production rate $(1 / \mathrm{d})$ uncorrected for fractionation; the multiple 0.5 represents lung water loss as $\mathrm{g} / 1 \mathrm{CO}_{2}$ (Prentice, 1988); the value of 500 represents an estimate of non-sweating transcutaneous water loss $(\mathrm{ml} / \mathrm{d})$; and $F_{\mathrm{H}_{2} \mathrm{O}}(\mathrm{ml} / \mathrm{d})$ is derived as $K_{\mathrm{D}} V_{\mathrm{D}} / I_{\mathrm{D}}$. The final term is a slight approximation since it does not incorporate any correction for fractionation.

$F_{\mathrm{CO}_{2}}$ values were converted to energy expenditure using classical indirect calorimetric equations (Weir, 1949) which require a value for the mean respiratory quotient (RQ) over the measurement period. Results are presented for an assumed RQ of 0.90 on the basis of 
the high carbohydrate: fat ratio in the diet (Black et al. 1986). The effect of recalculating the results using a mean RQ of 0.85 is also presented.

Propagation of error analysis as described by Coward et al. (1986) was performed on each measurement to obtain an estimate of individual errors. This calculation aggregates the individual errors on $K_{\mathrm{O}}, K_{\mathrm{D}}, I_{\mathrm{O}}$ and $I_{\mathrm{D}}$ before correcting for covariance between ${ }^{2} \mathrm{H}$ and ${ }^{18} \mathrm{O}$ enrichments. The computed errors, therefore, contain all measurement noise and real biological noise (day-to-day variation), but do not include possible error or bias introduced by inappropriate values for fractionation or $\mathrm{RQ}$, possible isotope sequestration or errors in the dose given. These are discussed fully elsewhere (Coward, 1988; Prentice, 1988; Schoeller, 1988).

The energy available for physical activity plus thermogenesis was calculated as TEE-RMR.

\section{Body composition}

Lean body mass (LBM) was calculated from each subject's deuterium space, derived by back-extrapolation of the disappearance curves to zero time. The water content of lean tissue was assumed to be $73.0 \%$ and fat mass was calculated as body-weight-LBM. Biceps, triceps, subscapular and suprailiac skinfolds were measured with Holtain calipers according to standard protocols.

\section{Dietary intake}

No measurements of food intake were performed in phase 1 in order to avoid any chance of compromising the truly non-intrusive, free-living nature of the isotope measurements. In phase 2, food intake was measured on 11 (SD 2) d (range 6-14 d) employing a weighed inventory technique which had been used in Keneba and the neighbouring villages for many years (Prentice, 1984). In brief this consisted of field-workers weighing and recording the eaten portion of each daily meal, and recording the intake of the very limited supply of snack foods by regular (three to four hourly) recall. Energy intake (EI) was calculated from a food table specifically constructed for the region by direct analysis of multiple samples of each food (Hudson et al. 1980; Paul \& Muller, 1980).

\section{Statistical analysis}

Linear regression analysis and Student's $t$ test were used.

\section{RESULTS}

Individual results for body composition, energy expenditure and energy intake (in phase 2 only) are presented in Table 2 .

\section{TEE}

TEE for all thirty women averaged 10.42 (SD 2.08) $\mathrm{MJ} / \mathrm{d}$ (range $6.33-14.68 \mathrm{MJ} / \mathrm{d}$ ) or 1.95 (SD 0.38) times RMR (range 1.15-2.60 times RMR). The mean propagated error was \pm 7.5 (SD $4 \cdot 2$ ) \%. Twelve subjects had a TEE in excess of $2 \cdot 0$ times RMR and four subjects exceeded 2.5 times RMR. The estimated errors on these four extremely high values averaged only $\pm 6.2 \%$, and close inspection of the raw values provided no grounds to question their validity. At the other extreme subject $22 \mathrm{~L}$ apparently expended only $1 \cdot 15$ times RMR. This result must be incorrect and was associated with a high estimated error of $\pm 15.9 \%$. On the principle that the error was random and would be offset by overestimates in other results it was not excluded from subsequent calculations involving TEE. The usual precision expected of the method in temperate climates (about $\pm 3.5 \%$ ), was compromised in the present study by the high levels of water turnover in the subjects. Mean water turnover (assessed as $K_{\mathrm{D}} D_{\mathrm{D}} / I_{\mathrm{D}}$ ) in Cambridge women has been measured at 
Table 2. Energy expenditure and body composition results of non-pregnant, non-lactating $(N P N L)$, pregnant $(P)$ and lactating (L) rural Gambian women in (a) phase 1 (late August and early September) and (b) phase 2 (2-3 weeks later in September in the following year)*

\begin{tabular}{|c|c|c|c|c|c|c|c|c|c|c|c|c|}
\hline \multirow[b]{2}{*}{ Group } & \multirow{2}{*}{$\begin{array}{c}\text { Subject } \\
\text { no. }\end{array}$} & \multirow{2}{*}{$\begin{array}{c}\text { Initial } \\
\mathrm{wt} \\
(\mathrm{kg})\end{array}$} & \multirow{2}{*}{$\begin{array}{c}\text { LBM } \\
(\mathrm{kg})\end{array}$} & \multirow{2}{*}{$\begin{array}{l}\text { Fat } \\
(\mathrm{kg})\end{array}$} & \multirow{2}{*}{$\begin{array}{c}\text { Wt } \\
\text { change } \\
(\mathrm{g} / \mathrm{d})\end{array}$} & \multirow{2}{*}{$\begin{array}{c}\text { TEE } \\
(\mathrm{kJ} / \mathrm{d})\end{array}$} & \multirow{2}{*}{$\begin{array}{c}\text { Estimated } \\
\text { error } \\
(\%)\end{array}$} & \multirow{2}{*}{$\begin{array}{l}\text { RMR } \\
(\mathrm{kJ} / \mathrm{d})\end{array}$} & \multirow{2}{*}{$\begin{array}{l}\text { TEE- } \\
\text { RMR } \\
(\mathrm{kJ} / \mathrm{d})\end{array}$} & \multirow{2}{*}{$\begin{array}{l}\text { TEE/ } \\
\text { RMR }\end{array}$} & \multicolumn{2}{|c|}{$\begin{array}{c}\text { Energy intake } \\
(\mathrm{kJ} / \mathrm{d})\end{array}$} \\
\hline & & & & & & & & & & & Mean & SD \\
\hline \multicolumn{13}{|c|}{ (a) Phase 1} \\
\hline NPNL & $\begin{array}{l}1 \\
2\end{array}$ & $\begin{array}{l}52 \cdot 1 \\
51 \cdot 4\end{array}$ & $\begin{array}{l}37 \cdot 9 \\
37 \cdot 0\end{array}$ & $\begin{array}{l}14 \cdot 2 \\
14 \cdot 4\end{array}$ & $\begin{array}{l}-96 \\
-32\end{array}$ & $\begin{array}{l}8426 \\
9699\end{array}$ & $\begin{array}{r} \pm 7.7 \\
+7.0\end{array}$ & $\begin{array}{l}4879 \\
5163\end{array}$ & $\begin{array}{l}3547 \\
4536\end{array}$ & $\begin{array}{l}1.73 \\
1.88\end{array}$ & & \\
\hline & 3 & $45 \cdot 0$ & $33 \cdot 6$ & $11 \cdot 4$ & -88 & 7971 & \pm 4.8 & 4422 & 3549 & 1.80 & & \\
\hline & 4 & $56 \cdot 1$ & $38 \cdot 9$ & $17 \cdot 2$ & +32 & 8586 & $\pm 6 \cdot 1$ & 5251 & 3335 & 1.64 & & \\
\hline & 5 & 46.5 & $29 \cdot 9$ & 16.6 & -16 & 6899 & \pm 6.1 & 5134 & 1765 & $1 \cdot 34$ & & \\
\hline & 6 & $48 \cdot 8$ & $38 \cdot 4$ & $10 \cdot 4$ & +38 & 10414 & \pm 5.8 & 5222 & 5192 & 1.99 & & \\
\hline & $50 \cdot 0$ & $35 \cdot 9$ & $14 \cdot 1$ & -27 & 8666 & \pm 6.3 & 5012 & 3654 & $1 \cdot 73$ & & \\
\hline \multicolumn{2}{|l|}{ SD } & $4 \cdot 1$ & $3 \cdot 5$ & $2 \cdot 7$ & 57 & 1248 & 1.0 & 318 & 1169 & 0.23 & & \\
\hline $\mathrm{P}$ & 7 & $71 \cdot 2$ & $51 \cdot 0$ & $20 \cdot 2$ & +64 & 11870 & \pm 6.6 & 7037 & 4833 & 1.69 & & \\
\hline & 8 & $38 \cdot 4$ & $32 \cdot 5$ & $5 \cdot 9$ & +62 & 9895 & \pm 5.1 & 4745 & 5150 & $2 \cdot 09$ & & \\
\hline & 9 & $60 \cdot 7$ & $47 \cdot 8$ & $12 \cdot 9$ & +117 & 10297 & $\pm 6 \cdot 1$ & 5477 & 4820 & $1 \cdot 88$ & & \\
\hline & 10 & $48 \cdot 6$ & $37 \cdot 8$ & $10 \cdot 8$ & -10 & 9071 & \pm 7.2 & 5176 & 3895 & $1 \cdot 75$ & & \\
\hline & 11 & $58 \cdot 5$ & $46 \cdot 1$ & $12 \cdot 4$ & +39 & 12510 & \pm 3.5 & 6054 & 6456 & 2.07 & & \\
\hline & 12 & $79 \cdot 8$ & $60 \cdot 5$ & $19 \cdot 3$ & +99 & 11385 & \pm 3.2 & 7305 & 4080 & 1.56 & & \\
\hline \multirow{2}{*}{\multicolumn{2}{|c|}{$\begin{array}{l}\text { Mean } \\
\text { SD }\end{array}$}} & $59 \cdot 5$ & $46 \cdot 0$ & $13 \cdot 5$ & +62 & 10838 & $\pm 5 \cdot 3$ & 5966 & 4872 & $1 \cdot 84$ & & \\
\hline & & $14 \cdot 9$ & 9.9 & $5 \cdot 4$ & 45 & 1301 & 1.7 & 1030 & 913 & 0.21 & & \\
\hline \multirow[t]{5}{*}{ L } & 13 & $49 \cdot 0$ & $44 \cdot 0$ & $5 \cdot 0$ & -4 & 10117 & \pm 11.9 & 5439 & 4678 & $1 \cdot 86$ & & \\
\hline & 14 & $59 \cdot 3$ & $42 \cdot 6$ & 16.7 & +49 & 12460 & \pm 11.8 & 5807 & 6653 & $2 \cdot 15$ & & \\
\hline & 15 & 54.5 & 41.9 & $12 \cdot 6$ & -10 & 12958 & \pm 12.6 & 5703 & 7255 & 2.27 & & \\
\hline & 16 & 66.8 & $48 \cdot 9$ & $17 \cdot 9$ & -29 & 9129 & \pm 13.7 & 6870 & 2259 & $1 \cdot 33$ & & \\
\hline & 17 & $44 \cdot 0$ & $37 \cdot 3$ & $6 \cdot 7$ & +50 & 8611 & \pm 14.7 & 5406 & 3205 & 1.59 & & \\
\hline Mean & & 54.7 & $43 \cdot 0$ & $11 \cdot 7$ & +1 & 10655 & $\pm 12 \cdot 9$ & 5845 & 4810 & 1.84 & & \\
\hline SD & & 8.9 & $4 \cdot 2$ & $5 \cdot 8$ & 34 & 1959 & $1 \cdot 2$ & 598 & 2149 & $0 \cdot 39$ & & \\
\hline \multicolumn{13}{|c|}{ (b) Phase 2} \\
\hline \multirow[t]{4}{*}{ NPNL } & 18 & $40 \cdot 8$ & $34 \cdot 5$ & $6 \cdot 3$ & -16 & 8908 & $\pm 5 \cdot 2$ & 4577 & 4331 & 1.95 & 5389 & 2218 \\
\hline & 19 & $55 \cdot 0$ & 47.0 & 8.0 & -63 & 14677 & \pm 6.6 & 5665 & 9012 & $2 \cdot 60$ & 8979 & 2515 \\
\hline & 20 & $43 \cdot 4$ & $37 \cdot 7$ & $5 \cdot 7$ & +7 & 10753 & \pm 6.9 & 4820 & 5933 & $2 \cdot 23$ & 5012 & 1870 \\
\hline & 21 & $54 \cdot 4$ & $42 \cdot 3$ & $12 \cdot \mathrm{I}$ & -138 & 14368 & \pm 5.5 & 5544 & 8824 & $2 \cdot 60$ & 4837 & 1360 \\
\hline \multirow{2}{*}{\multicolumn{2}{|c|}{$\begin{array}{l}\text { Mean } \\
\text { SD }\end{array}$}} & $48 \cdot 6$ & $40 \cdot 5$ & $8 \cdot 1$ & -52 & 12177 & \pm 6.0 & 5152 & 7025 & $2 \cdot 35$ & 6054 & \\
\hline & & $7 \cdot 0$ & $5 \cdot 5$ & $2 \cdot 9$ & 64 & 2815 & 0.8 & 535 & 2283 & 0.32 & 1963 & \\
\hline \multirow[t]{9}{*}{$\mathrm{L}$} & 22 & $49 \cdot 1$ & $41 \cdot 5$ & $7 \cdot 6$ & --32 & 6330 & \pm 15.9 & 5481 & 849 & $1 \cdot 15$ & 4058 & 1293 \\
\hline & 23 & 55.9 & $46 \cdot 1$ & 9.8 & -14 & 13531 & \pm 6.9 & 5243 & 8288 & $2 \cdot 58$ & 5054 & 1410 \\
\hline & 24 & $49 \cdot 0$ & $42 \cdot 1$ & 6.8 & -104 & 12828 & \pm 190 & 5364 & 7464 & $2 \cdot 39$ & 3812 & 1155 \\
\hline & 25 & 43.8 & $36 \cdot 1$ & $7 \cdot 7$ & -112 & 9506 & \pm 5.7 & 5180 & 4326 & 1.84 & 6121 & 774 \\
\hline & 26 & $44 \cdot 7$ & $39 \cdot 9$ & 4.8 & +33 & 11029 & \pm 3.7 & 5782 & 5247 & 1.91 & 3021 & 1013 \\
\hline & 27 & $43 \cdot 2$ & 35.0 & $8 \cdot 2$ & +1 & 9519 & \pm 1.6 & 4217 & 5302 & $2 \cdot 26$ & 3699 & 1732 \\
\hline & 28 & $45 \cdot 5$ & 37.9 & $7 \cdot 6$ & +52 & 10598 & $\pm 3 \cdot 1$ & 5180 & 5418 & $2 \cdot 05$ & 4502 & 812 \\
\hline & 29 & $42 \cdot 7$ & 38.4 & $4 \cdot 3$ & -5 & 11523 & \pm 5.6 & 4577 & 6946 & 2.52 & 2720 & 791 \\
\hline & 30 & $45 \cdot 8$ & $37 \cdot 7$ & $8 \cdot 1$ & +14 & 8791 & \pm 6.0 & 5243 & 3548 & 1.68 & 5155 & 2201 \\
\hline Mean & & 46.6 & $39 \cdot 4$ & $7 \cdot 2$ & -19 & 10406 & \pm 7.5 & 5141 & 5265 & $2 \cdot 04$ & 4238 & \\
\hline SD & & 42 & $3 \cdot 4$ & 1.7 & 56 & 2183 & 5.9 & 471 & 2240 & $0 \cdot 46$ & 1085 & \\
\hline
\end{tabular}

LBM, lean body mass; TEE, total energy expenditure; RMR, resting metabolic rate.

* Tables of the isotope values used to derive Table $2\left(K_{\mathrm{D}}, K_{\mathrm{O}}, V_{\mathrm{D}}, V_{\mathrm{O}}, I_{\mathrm{D}}, I_{\mathrm{O}}, F_{\mathrm{H}_{2} \mathrm{O}}, F_{\mathrm{CO}, 2}\right.$; for definitions, see p. 318) are available by request to A. M. Prentice. Fractionation assumption $0 \cdot 15$, respiratory quotient assumption 0.90 . 


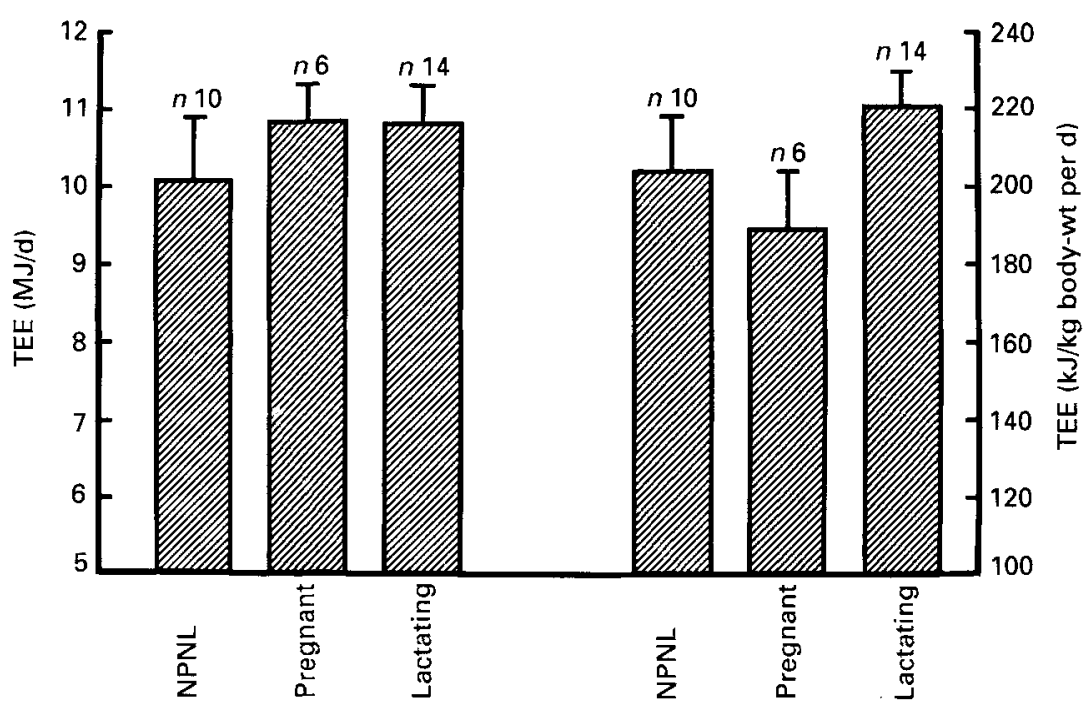

Fig. 2. Total energy expenditure (TEE) in non-pregnant, non-lactating (NPNL), pregnant and lactating rural Gambian women. Values are means with their standard errors represented by vertical bars for no. of subjects indicated. Values from phases 1 and 2 are combined (phase 1, late August and early September; phase 2, 2-3 weeks later in September; phases 1 and 2 being in consecutive years). For details of procedures for TEE measurement, see p. 317.

$3 \cdot 2(\mathrm{SD} 0.8) 1 / \mathrm{d}$ and in the present study was $5 \cdot 2(\mathrm{SD}) 1 \cdot 4) \mathrm{l} / \mathrm{d}$ with a range from 3.2 to $9 \cdot 0$ $1 /$ d. This increases the error by causing $F_{\mathrm{CO}_{2}}$ to be a smaller proportion of $F_{\mathrm{H}_{2} \mathrm{O}+\mathrm{CO}_{2}}$, decreasing the measured difference between the rate-constants for the two isotope disappearance curves. The particularly large propagated errors in subjects nos. $15,16,17$, 22 and 24 (Table 2 ) were all caused by high rates of water turnover $(6 \cdot 3,9 \cdot 0,6 \cdot 2,7 \cdot 2$ and $8 \cdot 21 /$ d respectively). This was additionally confirmed by a significant correlation between propagated error and the rate of water turnover $(r 0.719, P<0.001)$. The deterioration in precision is, therefore, an inevitable consequence of high water turnover and must be accepted when the DLW method is used in tropical climates. Nonetheless, the mean propagated error of $\pm 7.5 \%$ remains much smaller than the assumed errors of activity diary, factorial or heart-rate based estimates of energy expenditure. It should be emphasized that the $7.5 \%$ subsumes real biological noise (day-to-day variability) in addition to all methodological and instrumentation noise. Since DLW measurements are made over $14 \mathrm{~d}$ or longer, and since day-to-day variability is accounted for, the estimate of error relates to habitual energy expenditure rather than simply to energy expenditure measured over a limited time as in most other techniques.

Fig. 2 presents the combined values for phases 1 and 2 divided according to the different physiological states. There was a slight tendency for TEE $/ \mathrm{kg}$ to be lower in the $\mathbf{P}$ women, as would be anticipated on the basis of previous activity diary studies (Roberts et al. 1982; Lawrence \& Whitehead 1988), but none of the group differences was statistically significant.

Fig. 3 compares the current values expressed as the physical activity level (TEE/RMR) with values from affluent, inactive women in Cambridge, UK (Prentice et al. 1985) and against the recommended energy intakes for women in different work categories. The Gambian women's mean TEE corresponded to a moderate to heavy workload, and greatly exceeded that of the Cambridge women who were studied using the same 


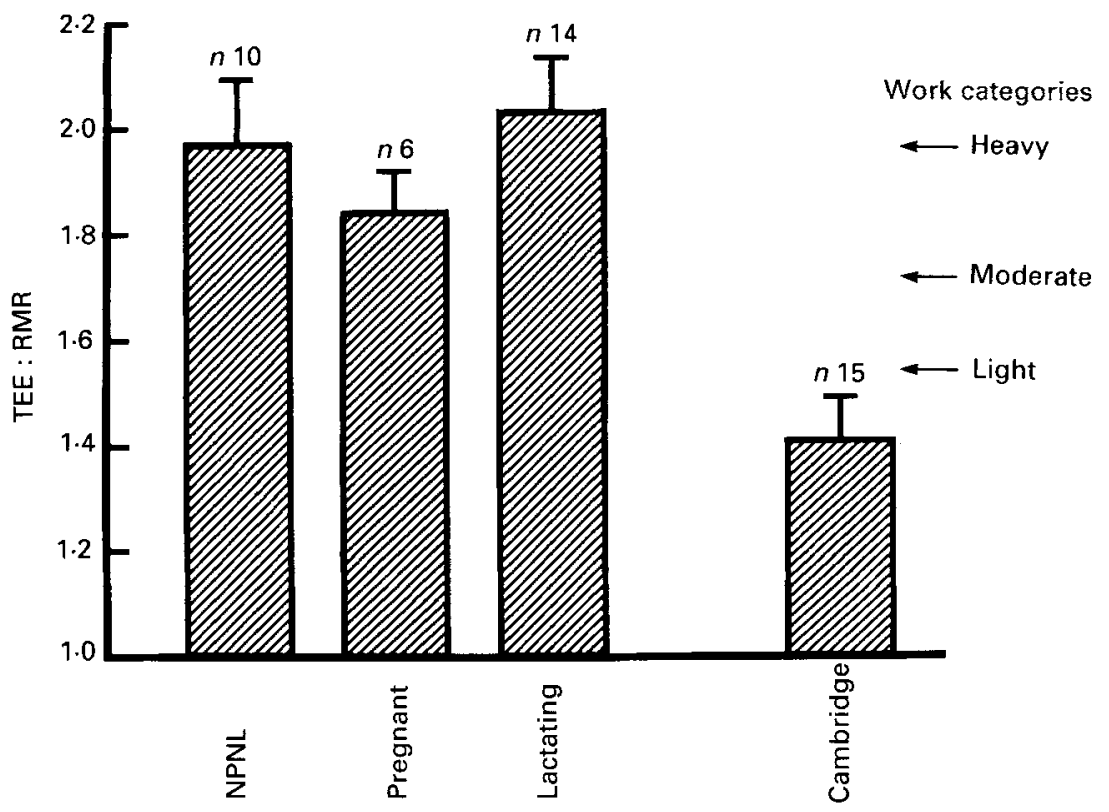

Fig. 3. Comparison of physical activity levels (total energy expenditure (TEE): resting metabolic rate (RMR)) for non-pregnant, non-lactating (NPNL), pregnant and lactating rural Gambian women and for Cambridge women. Values are means with their standard errors represented by vertical bars for no. of subjects indicated. For details of procedures see Methods. Calculated allowances for different work categories are illustrated for reference (Food and Agriculture Organization/World Health Organization/United Nations University, 1985).

experimental protocol. This is entirely consistent with the recorded time spent on farm work.

The absence of significant group differences allowed the values to be pooled for correlation analysis. (It should be noted that the energy deposited as new tissue in pregnancy or transferred during lactation is not measured in TEE and, therefore, does not compromise the pooling of values in this way. The energy costs of synthesis are included in TEE, but only amount to about $100 \mathrm{~kJ} / \mathrm{d}$ in pregnancy and $200 \mathrm{~kJ} / \mathrm{d}$ in lactation.) Linear regression indicated that body-weight had only a marginal influence on TEE accounting for $12 \%$ of the variance $(r 0.338, P=0.06)$. This correlation was entirely accounted for by the influence of body-weight on RMR $(r 0.871, P<0.001)$, since there was no association between body-weight and the energy cost of activity plus thermogenesis. LBM had a greater influence on TEE, accounting for $25 \%$ of the variance $(r 0.502$, $P<0.01)$. This was also largely accounted for by the dependence of RMR on LBM ( $r 0.847$, $P<0.001)$. TEE was not significantly related to body fatness expressed as percentage bodyweight $(r 0.293$, not significant) or to the rate of weight change during the measurement period ( $r 0 \cdot 115$, not significant, $\mathrm{P}$ subjects excluded).

\section{Activity plus thermogenesis}

The energy available for physical activity and thermogenesis (TEE - RMR) averaged 4.94 (SD 1.96) $\mathrm{MJ} /$ day (range 1.77-9.01 MJ/d, excluding subject 22L). The high level of interindividual variability (coefficient of variation $40 \%$ ) was largely accounted for by behavioural choices governing activity patterns, since TEE - RMR was not correlated with body-weight ( $r 0 \cdot 02$, not significant) or LBM ( $r 0 \cdot 246$, not significant), and expression of TEE-RMR with weight or LBM as the denominator, therefore, had little effect in 


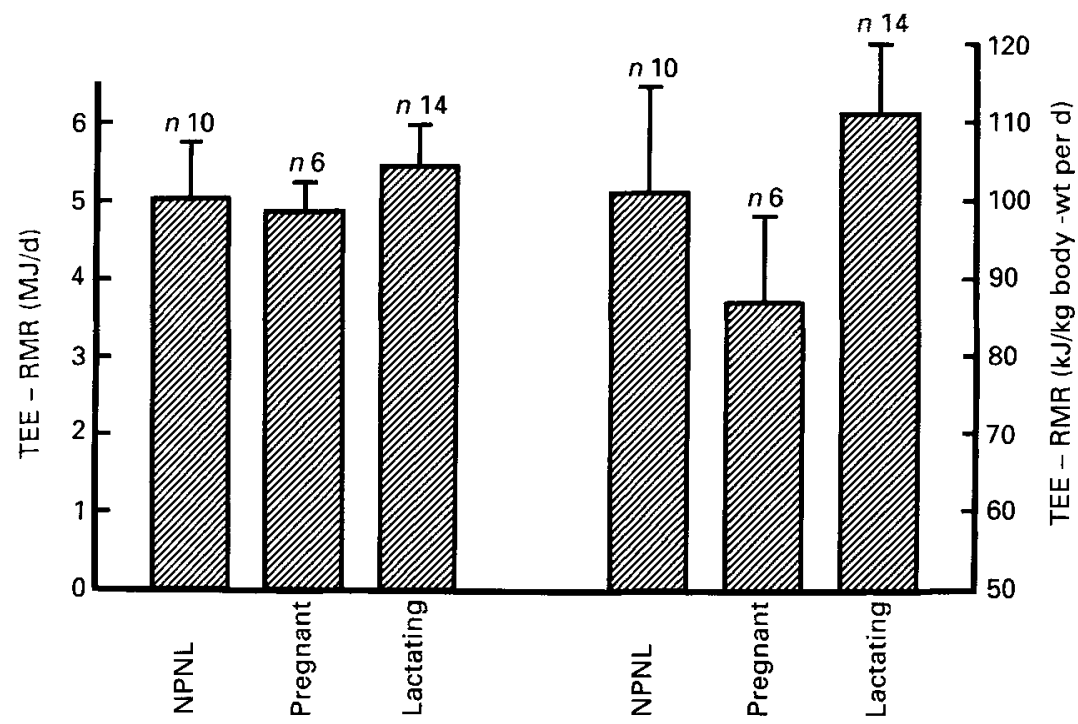

Fig. 4. Energy cost of physical activity plus thermogenesis in non-pregnant, non-lactating (NPNL), pregnant and lactating rural Gambian women. Values are means with their standard errors represented by vertical bars for no. of subjects indicated. TEE, total energy expenditure; RMR, resting metabolic rate. Values from phases 1 and 2 are combined (phase 1, late August and early September; phase 2, 2-3 weeks later in September; phases 1 and 2 being in consecutive years). For details of procedures see Methods.

reducing overall variance. However, percentage body fatness was inversely related to the amount of energy expended on activity $(r-0.423, P<0.025)$. This relationship is consistent with a number of explanations, such as that hard work is an important determinant of an individual's fatness, or that fat women manage to protect their body stores by remaining relatively inactive.

The values for TEE - RMR indicated that at this time of year the Gambian women were at least 2.5 times more active than women in Cambridge. When corrected for differences in body-weight the energy cost of activity plus thermogenesis was $(\mathrm{kJ} / \mathrm{kg}$ per d): Gambia 103 (SD 37) (range 34-164), Cambridge lean subjects 39 (SD 18) (range 20-95), Cambridge obese subjects 40 (SD 12) (range 31-74) (Prentice et al. 1986). Any group differences in dietinduced thermogenesis (DIT) are likely to be rather small and may represent at most a 3-5\% reduction in TEE in The Gambia (G. Minghelli, Y. Schutz, A. Charbonnier, R. Whitehead and E. Jequier, unpublished results). Any differences in thermoregulatory thermogenesis are also likely to be small and, due to the high ambient temperatures in The Gambia, will tend to counteract the likely differences in DIT. The total cost of these two thermogenic components is unlikely to exceed about $10 \%$ of TEE, equivalent to $10-15$ $\mathrm{kJ} / \mathrm{kg}$ per $\mathrm{d}$, and any differences between groups are unlikely to exceed $5 \mathrm{~kJ} / \mathrm{kg}$ per $\mathrm{d}$. Using these assumptions to eliminate thermogenesis from TEE-RMR would yield values for physical activity of approximately $90 \mathrm{~kJ} / \mathrm{kg}$ per $\mathrm{d}$ in The Gambia and $25 \mathrm{~kJ} / \mathrm{kg}$ per $\mathrm{d}$ in Cambridge: more than a $3 \cdot 5$-fold difference.

Fig. 4 illustrates the energy cost of activity and thermogenesis for the NPNL, P and L groups. There was no difference between the groups on an absolute basis, but when expressed per $\mathrm{kg}$ body-weight the $\mathrm{P}$ women appeared to be marginally less active than the other two groups $(P<0.05$ for $\mathrm{P} v$. NPNL and $\mathrm{L}$ groups combined). There was a significant negative correlation between body-weight and the proportion of the energy budget allocated to physical activity (body-weight $v$. TEE $-\mathrm{RMR} / \mathrm{kg}, r-0 \cdot 367, P<0.05$ ). 


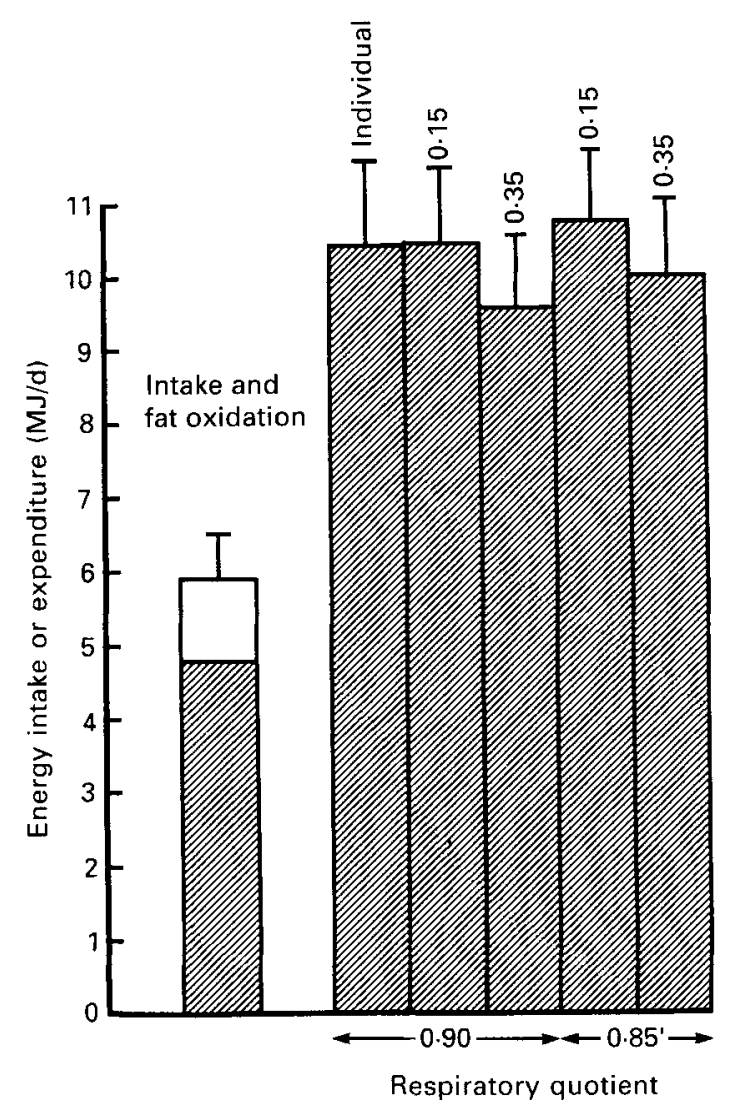

Fig. 5. Illustration of the computed effects of altering the fractionation and respiratory quotient assumptions used to calculate total energy expenditure (TEE). Values are means with their standard errors represented by vertical bars. Values from phase 2 only (2-3 weeks later in September than phase 1 of previous year).

This provides suggestive evidence that a low adult body-weight may be an effective adaptation which permits the smaller women to achieve a greater amount of useful physical work. This is consistent with preliminary results from children in The Gambia, which also suggest that growth retardation may be one of the most potent energy-sparing mechanisms (Vasquez-Velasquez, 1988).

\section{Food intake}

EI measured in phase 2 averaged only $4.80(\mathrm{SD} 1.58) \mathrm{MJ} / \mathrm{d}$ (range $2.72-8.98 \mathrm{MJ} / \mathrm{d}$ ) and represented only $44 \%$ of the isotopically-measured TEE (Fig. 5). The deficit in the lactating women was even greater than indicated in Table 2(b), since TEE does not include the energy transferred in milk. Milk output was not estimated in the present study, but previous measurements would suggest a transfer of close to $2 \mathrm{MJ} / \mathrm{d}$ (Prentice et al. 1981). Even excluding the energy content of milk, the mean energy imbalance (TEE-EI) that would have to be accounted for by endogenous fat oxidation was 6.08 (SD 2.56) $\mathrm{MJ} / \mathrm{d}$ and the minimum imbalance in any subject was $2.3 \mathrm{MJ} / \mathrm{d}$. These food intake results are only slightly lower than the 5-6 MJ/d observed in previous years (Prentice, 1984) and are consistent with the simple observation that food supplies were particularly short during this study. 


\section{Body composition}

The imprecision of currently available techniques for assessing body composition precluded their use for assessing the short-term changes in fat stores anticipated in the present study. For instance, even assuming $1 \%$ precision in estimating LBM by total body water measurements, this would lead to a predicted imprecision of $\pm 1.5-2.0 \mathrm{~kg}$ fat on an anticipated change of about $0.5-1.0 \mathrm{~kg}$ over the isotope measurement periods. Assessment of changes in body energy stores was, therefore, based on weight changes alone.

The average weight losses were - 10 (SD 51) g/d in the NPNL and L groups in phase 1, and -29 (SD 58) g/d in phase 2 . Assuming an energy equivalence of weight loss of $30 \mathrm{~kJ} / \mathrm{g}$ (i.e. assuming that weight loss is $75 \%$ fat) yields an endogenous energy supply of only 0.85 (SD 1.74) $\mathrm{MJ} / \mathrm{d}$ (range 4.14 to $-1.56 \mathrm{MJ} / \mathrm{d}$ ). This still leaves an unexplained difference between TEE and EI of more than $5 \mathrm{MJ} / \mathrm{d}$.

\section{Potential errors in the DLW method}

The values presented here were calculated using a fractionation assumption of 0.15 and a mean RQ of 0.90 . Fig. 5 shows the computed consequences of changing these assumptions. The fractionation assumption was changed either to the individual method of prediction (see p. 318) or to the mean value used in temperate studies $(0 \cdot 35)$. The former assumption alters the individual results by up to $5 \%$, but makes no difference to the average result. The latter assumption is totally unrealistic for the Gambian climate, but would still yield an average TEE in excess of $9.0 \mathrm{MJ} / \mathrm{d}$. A lower value than 0.15 would increase TEE by up to $2 \%$. Changing the RQ assumption to 0.85 , on the grounds that the contribution of endogenous fat to the total substrate mixture oxidized may be greater than allowed for using an RQ of 0.90 , would increase TEE by a few percent.

\section{DISCUSSION}

The present study has produced important findings in two different respects which will be discussed separately. The first relates to the massive discrepancy between the estimates of EI and Expenditure, and the methodological lessons that can be learnt. The second relates purely to the novel estimates of free-living energy expenditure in rural subsistence-farming women.

The study was initially designed to investigate how women modify their energy budget in order to cope under conditions of negative energy balance, and a substantial deficit between EI and expenditure was always anticipated. However, only a small proportion of the deficit could be accounted for by mobilization of fat stores, and one or more of the methods used must be in error.

The values for EI purported to represent total food intake and were broadly consistent, though somewhat lower, than measurements made by a number of different investigators during the same calendar months in previous years (Paul \& Muller, 1980; Prentice et al. 1981 ; Prentice, 1984). All meals were weighed by field-workers and any uneaten portions were reweighed. The field-workers were in very regular contact with the subjects throughout each measurement day and recorded any snack foods by observation or by recall at three to four hourly intervals. It should be noted that cultivated, purchased or 'bush' snack foods are extremely scarce at this time of year, and this must be considered a most unlikely source of major error in the particular women studied. Both meal and snack food net weights were converted to metabolizable energy using computerized food tables specifically constructed for use in this region of The Gambia and derived by multiple analyses of all food types (Hudson et al. 1980). Values for the major food types have 
recently been rechecked and confirmed as valid. Measurements of faecal energy losses were not performed because of cultural resistance to faecal collections, but since gross and metabolizable energy values only differ by $10-15 \%$, an enhanced efficiency of food energy extraction cannot represent a very important source of error.

The calculation of energy derived from body fat oxidation is clearly a potential source of error, but it is inconceivable that this could explain more than a small proportion of the $5.2 \mathrm{MJ} / \mathrm{d}$ deficit. A weight loss of $173 \mathrm{~g} / \mathrm{d}$ or $5 \cdot 25 \mathrm{~kg} / \mathrm{month}$ would be required to account for the deficit using the same energy equivalence of weight loss assumed here $(30 \mathrm{~kJ} / \mathrm{g})$. If it were assumed that the weight loss consisted of pure lipid the energy equivalence would only rise by $30 \%$ to $39 \mathrm{~kJ} / \mathrm{g}$. The only way that the relatively small weight loss could account for the apparent energy deficit would be if $5 \mathrm{~kg}$ lipid was oxidized each month and replaced by $5 \mathrm{~kg}$ water. This can be definitely excluded on the basis of previous total body water measurements in large numbers of similar subjects in Keneba (Lawrence et al. $1987 a$ ).

The final technique that must be scrutinized for potential bias is the DLW method. The greatest onus of proof lies with this method simply because it is novel and relatively untried in humans. Nonetheless, we believe the estimates of TEE to be close to the true value for the following reasons. First, they are intuitively sound, in view of the fact that the women spend long hours involved in relatively strenuous farming and domestic tasks and are certainly considerably more active then their affluent counterparts in developed countries. In contrast, the food intake measurements have always been intuitively difficult to accept particularly after it had been demonstrated that basal metabolism in Gambian women is not greatly reduced (Lawrence et al. $1987 \mathrm{~b}$ ). The DLW estimates of TEE closely matched estimates derived by activity diary in other groups of women at the same time of year (Lawrence et al. 1987a; Lawrence \& Whitehead, 1988).

Examination of the DLW method itself indicates that significant bias is unlikely. The technique has been independently cross-validated against indirect calorimetry by several laboratories in both small animals and man. Although the reported levels of precision vary widely, none of these validation studies has indicated any significant uni-directional bias in the DLW method (Schoeller, 1988; Prentice, 1988). In our laboratory a validation study against continuous $12 \mathrm{~d}$ whole-body calorimetry yielded a mean error of only $1.9 \%$, with a coefficient of variation also of $1.9 \%$ (Coward et al. 1985). Fig. 5 illustrates that the TEE results cannot be substantially biased by the assumptions made for the fractionation and RQ values. The final potential sources of error in field application of the DLW method arise from potential changes in natural isotopic background levels during the measurement, potential changes in the isotope dilution spaces and isotope sequestration during tissue or fat synthesis in pregnancy or lactation. We have calculated that these are unlikely to generate an error in TEE in excess of $\pm 1 \%$ (Prentice, 1988).

In view of the previously mentioned calculations we are forced to conclude that the most likely source of error lies in the food intake measurements. As a consequence of these findings we have devoted a considerable amount of additional effort in trying to detect how and why the measurements can have been so far wrong. It seems likely that the most important factor may be a variant of the observer effect, in which habitual behaviour patterns are altered when under observation. One way in which our method could have contributed to this is that we have always asked the subjects to serve their food into individual bowls on the day of observation rather than eat from a communal bowl. Since we were aware that this may have suppressed intake we tested the effect of continuing the measurement for 10 $\mathrm{d}$. Under these conditions the subjects would have become very hungry after 1 or $2 \mathrm{~d}$ and should increase their intake accordingly. This test showed a slight increase with time, but it was far too small to account for the present deficit (J. Singh, unpublished results). Similarly, attempts have been made to observe snack food intakes covertly whilst 
ostensibly recording activity patterns or mother-child interactions. This produced a higher intake at times of year when snack foods were more easily obtained, but had little influence during the hungry period studied here. Other possible explanations seem rather far-fetched, but cannot be excluded. For instance, since there are strong communal pressures to share food stocks when times are hard the villagers may attempt to conceal the extent of their food supplies both from other villagers and their neighbours by eating at night. Our indigenous field-staff assert that this does not occur, and it would in any case be extremely difficult since all the staple foods require pounding and cooking which would be easily detectable. In summary we are still unable to identify the source of our error.

The conclusion that our food intake measurements were substantially in error may have profound implications for international nutrition, since few published studies have invested more time or effort in measuring food intake than those in Keneba. Our observed EI during the dry season, although low, are matched by many similar reported intakes from other underprivileged societies in the developing world (Prentice, 1980, 1984). Few of these claimed intakes have been substantiated by testing for weight stability when subjects are fed the reported intakes under controlled conditions (Ashworth, 1968; Durnin, 1979). It seems likely, therefore, that many of the estimates are substantially wrong, as previously suspected (James \& Shetty, 1982), and that many of the resultant conclusions concerning adaptive responses to low energy intakes may need to be re-examined. DLW measurements are also revealing that food intake may often be seriously under-estimated in studies in affluent societies (Prentice et al. 1986; Livingstone et al. 1989).

Fortunately, this apparent invalidation of our food intake measurements has little impact on previous conclusions derived from this community, since we have rarely used the values to make any quantitative 'balance' calculations. Instead the values have been used to substantiate the fact that the population is chronically undernourished and subjected to additional periods of acute malnutrition during the hungry period. In this respect they were only one of many indicators, and the others, such as absolute body fat content, weight changes and biochemical variables, still confirm these basic assumptions.

Turning to the estimates of TEE, the present study has demonstrated that the DLW technique is confirming its initial promise as an extremely robust field method for assessing TEE in genuinely free-living subjects. On the basis of the calculations described previously and summarized in Fig. 5, it seems extremely unlikely that the results are inaccurate by more than a few percent.

The measurements demonstrated that the Gambian women managed to sustain remarkably high levels of energy expenditure in spite of being in negative energy balance. The motivation for maintaining such a high level of work performance is clearly very high since crop production is a matter of survival, and climatic conditions ensure that the agricultural work is concentrated into a relatively short space of time. The findings on the specific costs of activity (plus a minor component of thermogenesis), calculated as TEE-RMR, are the first of their kind from rural subsistence farmers in the developing world and, when expressed per $\mathrm{kg}$ body-weight, allow direct comparison with other subject groups. When compared using exactly the same method, the Gambian women were shown to expend 3.5 times as much energy as the Cambridge women. They may arguably have achieved an even greater relative amount of actual work done, since there is some evidence that they can perform certain standard tasks with a greater metabolic or physical efficiency (Lawrence et al. 1987b).

The authors are grateful to Lamin Colley, Bill Lamb, Frances Foord and Mark Lawrence for providing assistance with the field aspects of this study and to the subjects for their cooperation. E. D. is supported by the Nestlé Foundation. 


\section{REFERENCES}

Ashworth, A. (1968). An investigation of very low calorie intake reported in Jamaica. British Journal of Nutrition 22, 342-345.

Black, A. E., Prentice, A. M. \& Coward, W. A. (1986). Use of food quotients to predict respiratory quotients for the doubly-labelled water method of measuring energy expenditure. Human Nutrition: Clinical Nutrition 40C, $381-391$.

Bleiberg, F., Brun, T. A., Goihmon, S. \& Lippman, D. (1981). Food intake and energy expenditure of male and fernale farmers from Upper Volta. British Journal of Nutrition 45, 505-515.

Cole, T. J. (1989). In First Report on World Nutrition: First Update. UN Administrative Committee on Coordination Subcommittee on Nutrition, p. 35. New York: United Nations.

Coward, W. A. (1988). The ${ }^{2} \mathrm{H}_{2}{ }^{18} \mathrm{O}$ method-principles and practice. Proceedings of the Nutrition Society 47, 209-218.

Coward, W. A. \& Prentice, A. M. (1985). Isotope method for the measurement of carbon dioxide production in man. American Journal of Clinical Nutrition 41, 659-661.

Coward, W. A., Prentice, A. M., Murgatroyd, R. P., Davies, H. L., Cole, T. J., Sawyer, M., Goldberg, G. R., Halliday, D. \& Mcnamara, J. P. (1985). Measurement of $\mathrm{CO}_{2}$ and water production rates in man using ${ }^{2} \mathrm{H},{ }^{18} \mathrm{O}$. labelled $\mathrm{H}_{2} \mathrm{O}$; comparisons between calorimeter and isotope values. In Human Energy Metabolism, pp. 126-128 [A. J. H. van Es, editor]. Wageningen: Euro-Nutr.

Coward, W. A., Roberts, S. B., Prentice, A. M. \& Lucas, A. (1986). The ${ }^{2} \mathrm{H}_{2}{ }^{18} \mathrm{O}$ method for energy expenditure measurements - clinical possibilities, necessary assumptions and limitations. In Clinical Nutrition and Metabolic Research, Proceedings of 7th ESPEN Congress, pp. 169-177. Basel: Karger.

Dugdale, A. E. \& Payne, P. R. (1987). A model of seasonal changes in energy balance. Ecology of Food and Nutrition 19, 231-245.

Durnin, J. V. G. A. (1979). Energy balance in man with particular reference to low intakes. Bibliotheca Nutricia et Dietetica 27, 1-10.

Food and Agriculture Organization/World Health Organization/United Nations University (1985). Report of a Joint Expert Consultation. Energy and Protein Requirements. WHO Technical Report Series no. 724. WHO: Geneva.

Hudson, G. J., John P. M. V. \& Paul, A. A. (1980). Variation in the composition of Gambian foods: the importance of water in relation to energy and protein content. Ecology of Food Nutrition 10, 9-17.

James, W. P. T. \& Shetty, P. S. (1982). Metabolic adaptations and energy requirements in developing countries. Human Nutrition: Clinical Nutrition 36C, 33I-336.

Lawrence, M. (1988). Day-to-day variations in the energy expenditure of rural Gambian women. Proceedings of the Nutrition Society 47, 39A.

Lawrence, M., Coward, W. A., Lawrence, F., Cole, T. J. \& Whitehead, R. G. (1987a). Fat gain during pregnancy in rural African women: the effect of season and dietary status. American Journal of Clinical Nutrition 45, $1442-1450$.

Lawrence, M., Lawrence, F., Coward, W. A., Cole, T. J. \& Whitehead, R. G. (1987b). Energy requirements of pregnancy in The Gambia. Lancet ii, 1072-1976.

Lawrence, M. \& Whitehead, R. G. (1988). Physical activity and total energy expenditure of child-bearing Gambian village women. European Journal of Clinical Nutrition 42, 145-160.

Lifson, N., Gordon, G. B. \& McClintock, R. (1955). Measurement of total carbon dioxide production by means of $\mathrm{D}_{2}{ }^{18} \mathrm{O}$. Joumal of Applied Physiology 7, 704-710.

Lifson, N. \& McClintock, R. (1966). Theory of the use of the turnover rates of body water for measuring energy and material balance. Journal of Theoretical Biology 12, 46-74.

Livingstone, M. B. E., Strain, J. J., Nevin, G. B., Barker, M. E., Hickey, R. J., McKenna, P. G., Prentice, A. M. Coward, W. A. \& Whitehead, R. G. (1989). The use of weighed dietary records and the doubly-labelled $\left({ }^{2} \mathrm{H}_{2}{ }^{18} \mathrm{O}\right)$ water methods to compare energy intake and expenditure. Proceedings of the Nutrition Society 48 , 2 LA.

Norgan, N. G., Ferro-Luzzi, A. \& Durnin, J. V. G. A. (1974). The energy and nutrient intake and the energy expenditure of 204 New Guinean adults. Transactions of the Royal Society London, Ser. B 268, 309-348.

Paul, A. A. \& Muller, E. M. (1980). Seasonal variations in dietary intake in pregnant and lactating women in a rural Gambian village. In Maternal Nutrition during Pregnancy and Lactation, pp. 105-106 [H. Aebi and R. G. Whitehead, editors]. Berne: Hans Huber.

Prentice, A. M. (1980). Variations in maternal dietary intake, birthweight and breastmilk output in The Gambia. In Maternal Nutrition during Pregnancy and Lactation, pp. 167-183 [H. Aebi and R. G. Whitehead, editors]. Berne: Hans Huber.

Prentice, A. M. (1984). Adaptations to long-term low energy intake. In Energy Intake and Activity, pp. 1-30 [E. Pollitt and P. Amante, editors]. New York: Alan R. Liss Inc.

Prentice, A. M. (1988). Applications of the ${ }^{2} \mathrm{H}_{2}{ }^{18} \mathrm{O}$ technique in free-living adults. Proceedings of the Nutrition Society 47, 259 -268.

Prentice, A. M., Black, A. E., Coward, W. A., Davies, H. L., Goldberg, G. R., Murgatroyd, P. R., Ashford, J., Sawyer, M. \& Whitehead, R. G. (1986). High levels of energy expenditure in obese women. British Medical Journal 292, 983-987. 
Prentice, A. M., Coward, W. A., Davies, H. L., Murgatroyd, P. R., Black, A. E., Goldberg, G. R., Ashford, J. \& Sawyer, M. (1985). Unexpectedly low levels of energy expenditure in healthy women. Lancet i, 1419-1422.

Prentice, A. M., Whitehead, R. G., Roberts, S. B. \& Paul, A. A. (1981). Long-term energy balance in childbearing Gambian women. American Journal of Clinical Nutrition 34, 2790-2799.

Roberts, S. B., Paul, A. A., Cole, T. J. \& Whitehead, R. G. (1982). Seasonal changes in activity, birth weight and lactational performance in rural Gambian women. Transactions of the Royal Society of Tropical Medicine and Hygiene 76, 668-678.

Schoeller, D. A. (1983). Energy expenditure from doubly-labelled water: some fundamental considerations in humans. American Journal of Clinical Nutrition 38, 999-1005.

Schoeller, D. A. (1988). Measurement of energy expenditure in free-living humans using doubly-labelled water. Journal of Nutrition 118, 1278-1289.

Schoeller, D. A., Leitch, C. A. \& Brown, C. (1986). Doubly-labelled water method: in vivo oxygen and hydrogen isotope fractionation. American Journal of Physiology 251, R1137-R1143.

Schoeller, D. A. \& Taylor, P. B. (1987). Precision of the doubly labelled water method using the two-point calculation. Human Nutrition: Clinical Nutrition 41C, 215-223.

Schoeller, D. A. \& van Santen, E. (1982). Measurement of energy expenditure in humans by the doubly-labelled water method. Journal of Applied Physiology 53, 955-959.

Vasquez-Velasquez, L. (1988). Energy expenditure and physical activity of malnourished Gambian infants. Proceedings of the Nutrition Society 47, 233-239.

Weir, J. B. de V. (1949). New methods for calculating metabolic rate with special reference to protein metabolism. Journal of Physiology 109, 1-9. 